\title{
PROCESSO DECISÓRIO NA EXPLORAÇÃO E PRODUÇÃO DE PETRÓLEO
}

\section{THE DECISION-MAKING PROCESS IN THE PETROLEUM EXPLORATION AND PRODUCTION}

\section{Autor Principal}

Angelo Milani Júnior, M.Sc. Administração de Empresas (Fundação Getúlio Vargas - São Paulo - Brasil)

Instituição: PETROBRAS - Unidade de Negócios Bolívia

Cargo: Gerente de Planejamento e Controle de Gestão

Endereço: Av. San Martin n ${ }^{\circ} 1700$ - Edifício Centro Empresarial Equipetrol - $2^{\text {do }}$ Piso Casilla de Correo 6866 - Santa Cruz de la Sierra - Bolívia.

Fone: (591-3) 366-7095

Fax: (591-3) 366-7257

E-mail: angelomilani@petrobras.com.bo

\section{Demais Autores}

José Vitor Bomtempo, D.Sc. Economia Industrial (Ecole des Mines de Paris - França) Instituição: Escola de Química - Universidade Federal do Rio de Janeiro (EQ/UFRJ)

Cargo: Professor Adjunto II do Departamento de Engenharia Química (DEQ)

Endereço: Ilha do Fundão - Cidade Universitária - COPPE - Bloco E - Sala 211 - Rio de Janeiro - RJ - CEP 21.949-900

Fone: (21) 2562-7610

Fax: (21) 2562-7567

E-mail: vitor@eq.ufrj.br

Helder Queiroz Pinto Júnior, D.Sc. Economie et Politique de L'Energie (Université de Grenoble II - França)

Instituição: Instituto de Economia Industrial - Universidade Federal do Rio de Janeiro (IE/UFRJ)

Cargo: Professor Adjunto do Instituto de Economia (IE)

Endereço: Av.Pasteur, 250 - Sala 19 - Urca - Rio de Janeiro - RJ - CEP 22.290-240

Fone: (21) 3873-5270

Fax: (21) 2541-8148

E-mail: helder@ie.ufrj.br 


\title{
RESUMO
}

Este trabalho propõe a formulação de modelos de negócios para apoiar o processo decisório em organizações complexas. O processo decisório é estudado, explorando-se os temas da racionalidade limitada, da estruturação de problemas, dos modelos mentais, dos mundos virtuais e da modelagem como apoio à decisão. A dinâmica de sistemas é introduzida como um instrumento para a construção de modelos, a identificação de regras de decisão e sua comunicação. É sugerida a abordagem ambiente-estratégia-recursos para a definição de estratégias. É desenvolvido um modelo de negócios para as atividades do segmento exploração e produção de petróleo, para proporcionar aos gerentes condições de decidir sobre estratégias que gerem vantagens competitivas ao conciliar as abordagens baseadas no mercado e em recursos. Conclui-se o trabalho com a descrição de estratégias, diretrizes e condicionantes relevantes para o processo de tomada de decisão.

Palavras-chave: processo decisório, dinâmica de sistemas, indústria do petróleo.

\begin{abstract}
This work proposes the formulation of business models to support the decision-making process in complex organizations. The decision-making process is studied, being explored the themes of the bounded rationality, of the problems' structuring, of the mental models, of the virtual worlds and of the modeling as support to the decision. The system dynamics is introduced as an instrument for models' construction, the identification of decision's rules and its communication. The environment-strategy-resources approach is suggested for the definition of strategies. A businesses model is developed for the activities of exploration and production of the petroleum segment, to providing the managers of conditions to decide about strategies that generate competitive advantages when reconciling the approaches based on market and on resources. The work is concluded with the description of the strategies, guidelines and relevant conditionalities for the decision-making process.
\end{abstract}

Key words: decision-making process, system dynamics, petroleum industry. 


\section{INTRODUÇÃO}

A tomada de decisão em organizações complexas é uma tarefa difícil e imperfeita devido às limitações da mente humana para formular e resolver problemas complexos. Embora a abordagem clássica para o processo decisório preconize a escolha racional, onde os fins estão claramente relacionados aos meios, e onde tudo é conhecido, na prática as pessoas decidem com base em modelos mentais tácitos e simplificados da realidade. Uma abordagem alternativa à escolha racional é, portanto, a construção de mundos virtuais. Os mundos virtuais são sistemas compostos por variáveis inter-relacionadas cujo comportamento é regulado por regras de decisão para a explicitação, o compartilhamento e o aperfeiçoamento dos modelos mentais de um grupo de pessoas.

A inquietude com esses temas motivou os autores a desenvolverem uma pesquisa cujos resultados parciais são apresentados neste texto, em cinco seções. A primeira seção aborda o Processo Decisório através de uma descrição da escolha racional e da racionalidade limitada. Em seguida, a estruturação de problemas é apresentada como um processo de modelagem das questões em análise e de seu entorno e, por fim, sugere-se a construção de mundos virtuais para simular a realidade e antecipar as conseqüências das decisões.

Na segunda seção a Dinâmica de Sistemas é apresentada como um instrumento de análise e modelagem para construir mundos virtuais, identificar políticas (regras de decisão), sejam elas explícitas ou tácitas, e comunicá-las de forma objetiva. Nesta segunda seção descrevem-se os principais conceitos da dinâmica de sistemas: anéis de retroalimentação, estoques e fluxos, natureza do processo decisório e políticas.

$\mathrm{Na}$ terceira seção descrevem-se os principais processos da Indústria do Petróleo e seus respectivos conceitos, de forma a preparar o leitor para a apresentação do Modelo de Negócios.

Na quarta seção é desenvolvido um Modelo de Negócios para o Segmento Exploração e Produção de Petróleo que é a contribuição original deste texto. Esta seção começa pela descrição da abordagem ambiente-estratégia-recursos, prossegue com a aplicação dos conceitos da dinâmica de sistemas no desenvolvimento do modelo de negócios e com a explicitação das estratégias, diretrizes e condicionantes relevantes para o processo de tomada de decisão. Finaliza com uma análise do modelo desenvolvido. A quinta seção apresenta as conclusões do trabalho. 


\section{PROCESSO DECISÓRIO}

Grande parte do tempo dos gerentes e executivos é dedicado a decidir. Em conseqüência, grande parte da pesquisa acadêmica em administração é dedicada ao estudo do processo decisório. A abordagem clássica preconiza a escolha racional, onde os fins estão claramente relacionados aos meios, e onde tudo é conhecido.

Os fundamentos da abordagem clássica de escolha racional não resistem aos fatos. Em muitas situações complexas, existem incerteza e risco consideráveis sobre as conseqüências de escolhas que deveriam ser feitas. É, também, pouco provável que o responsável pela decisão tenha informações completas sobre todas as opções possíveis. Por fim, a complexidade de muitos problemas de decisão significa que o tomador de decisão é incapaz de calcular o melhor curso de ação, mesmo se todas as opções forem conhecidas. Insatisfeito com a abordagem clássica de escolha racional, Herbert Simon propôs o conceito de racionalidade limitada:

A capacidade da mente humana de formular e resolver problemas complexos
é muito pequena comparada com o tamanho do problema cuja solução é
requerida para um comportamento racional objetivo no mundo real ou, até,
para uma aproximação razoável a tal racionalidade objetiva. (SIMON, 1957,
p. 198).

As questões que são objeto de decisão ocorrem em ambientes complexos que necessitam ser corretamente compreendidos. Esse entendimento se dá através da estruturação de problemas.

De acordo com Pidd (1998, p. 88), “... a estruturação de problemas é uma forma de exploração na qual o analista desenvolve um mapa daquilo que está ocorrendo e do que poderia ser feito sobre ele."

Ackoff, em suas obras de 1974 e 1979 combina a formulação e a solução de questões em três categorias: enigmas, problemas e confusões. Eles são constructos sociais, ou seja, estão definidos aos olhos do observador. Embora os fatos sejam claros e objetivos, a interpretação desses fatos varia de pessoa para pessoa. Segundo Goffman (1974), as pessoas compreendem os eventos empregando um esquema de interpretação (uma estrutura). Ao passar por alguma nova experiência, as pessoas tendem a interpretá-la sob a luz de suas molduras de referência, mesmo que não estejam conscientes delas. Goffman denominou esta ação de enquadramento.

Vennix (1990), Doyle e Ford (1998) e Sterman (2000) descrevem fenômeno semelhante sob a denominação de modelos mentais. Segundo estes autores, os modelos 
mentais são descritos em psicologia e filosofia como rotinas, procedimentos padrão, mapas cognitivos, tipologias para classificação de experiências, estruturas lógicas para interpretação de linguagem ou atributos de indivíduos.

Em suma, a estruturação de problemas consiste em desenvolver uma definição do problema que está sendo analisado, sem perder de vista a relação entre ele e o seu entorno, ou seja, consiste em desenvolver um "mapa" daquilo que está ocorrendo e do que poderia ser feito sobre ele.

O "mapa" resultante da estruturação de problemas é um modelo:

Um modelo é uma representação externa e explícita de parte da realidade vista pela pessoa que deseja usar aquele modelo para entender, mudar, gerenciar e controlar parte daquela realidade. (PIDD, 1998, p. 25).

Os modelos são também chamados de mundos virtuais (SCHÖN, 1982) e de micromundos (PAPERT, 1980). Os mundos virtuais permitem simular a realidade e antecipar as conseqüências das decisões.

\section{DINÂMICA DE SISTEMAS}

A dinâmica de sistemas, inicialmente denominada "dinâmica industrial", foi desenvolvida por Jay Wright Forrester, do Massachusetts Institute of Technology, a partir das idéias de Arnold Tustin (1953) sobre as similaridades entre os sistemas econômicos e os servomecanismos eletromecânicos. Nas palavras de Forrester, a dinâmica industrial era assim definida:

Dinâmica industrial é uma forma de estudar o comportamento dos sistemas industriais para mostrar como diretrizes, decisões, estruturas e retardos se inter-relacionam para influenciar o crescimento e a estabilidade. (FORRESTER, 1961, p.vii).

Em muitos sistemas humanos, o controle é exercido por processos de retroalimentação (feedback) que usam informações como base para a ação. Esta informação é freqüentemente atrasada e pode estar distorcida, e estes fatores precisam ser levados em consideração ao se analisar como os sistemas humanos são gerenciados. A dinâmica de sistemas provê uma forma de modelar tais sistemas humanos com seus processos de retroalimentação, atrasos e distorções. Isto é feito através de uma simples analogia com sistemas hidráulicos, cuja atividade é representada por fluxos e estoques.

Segundo Sterman (2000, p.vii), a dinâmica de sistemas tem sido utilizada por muitas companhias, empresas de consultoria e órgãos governamentais. Universidades e escolas de negócios estão expandindo a oferta de cursos. É crescente o número de aplicações bem 
sucedidas de seus métodos de modelagem. Há aplicações nas mais diversas áreas do conhecimento. Corben, Stevenson e Wolstenholme (1999) apresentam uma aplicação à indústria do petróleo, Hafeez e Abdelmeguid (2003) à gestão do conhecimento e Dyner e Franco (2004) aos mercados de energia.

Modelar sistemas dinâmicos é descobrir e representar os processos de retroalimentação que determinam a dinâmica de um sistema, juntamente com estruturas de estoque e fluxo, retardos de tempo e não linearidades. Toda a dinâmica origina-se da interação de apenas dois tipos de anéis de retroalimentação, anel positivo (ou auto-reforço) e anel negativo (ou autocorreção). Os anéis positivos tendem a reforçar ou amplificar o que está acontecendo no sistema. Os anéis negativos se opõem à mudança.

Denomina-se diagrama de anel causal (causal loop diagram - CLD) à representação da estrutura de retroalimentação de um sistema através de variáveis conectadas por flechas denotando as influências causais entre essas variáveis e explicitando os anéis de retroalimentação que interagem no sistema.

Todos os sistemas, independentemente da complexidade, consistem de malhas (networks) de retroalimentações (feedbacks) positivas e negativas, e toda a dinâmica se origina da interação desses anéis (loops) entre si. (STERMAN, 2000, p. 12).

Diagramas de anel causal são extremamente úteis em muitas situações, mas sofrem de uma série de limitações. Uma das mais importantes é a incapacidade de capturar a estrutura de estoque e fluxo do sistema.

Estoques são acumulações. Eles caracterizam o estado do sistema e geram a informação na qual as decisões e ações são baseadas. Devido ao desacoplamento das taxas de fluxo, os estoques são a fonte da dinâmica do desequilíbrio nos sistemas.

A dinâmica de sistemas tem uma abordagem peculiar para o processo decisório, pelo qual a informação é convertida em ação. Em sua obra seminal, Forrester (1961, p. 95) define ponto de decisão como um ponto de controle da taxa de fluxo do diagrama de estoques e fluxos de um sistema. Uma decisão é baseada no estado do sistema, o qual é representado pela condição de vários níveis de estoques.

Segundo Forrester (1994, p. 54-56), alguns níveis descrevem o estado aparente das condições reais, outros o estado desejado. Níveis são as entradas para o fluxo de decisões. Decisões controlam taxas de fluxo entre estoques. As taxas de fluxo causam mudanças nos níveis dos estoques. Mas taxas de fluxo não são entradas para as decisões. As taxas de fluxo instantâneas atuais são, em geral, não mensuráveis e desconhecidas, e não podem afetar 
decisões instantâneas atuais. Apenas taxas de fluxo resultantes de decisões alteram níveis de estoques. Apenas níveis de estoques controlam decisões e taxas de fluxo.

A palavra política (policy) é utilizada em dinâmica de sistemas de forma ampla para descrever como o processo decisório converte informação em ação. Segundo Forrester (1994, p. 58), "Uma política é uma declaração formal que define a relação entre as entradas de informação e os fluxos de decisão resultantes". Políticas são freqüentemente referidas na literatura como regras de decisão.

\section{INDÚSTRIA DO PETRÓLEO}

A indústria do petróleo pode ser descrita através de um grande processo, composto de seis atividades, que vão "do poço ao posto": exploração, explotação, produção, refino, transporte e distribuição. Em uma abordagem mais ampla, podem ser acrescentados a geração de energia termelétrica a partir do gás natural, a petroquímica, os serviços de sondagem e o apoio logístico. Este grande processo pode ser segmentado de diversas formas. Uma forma bastante comum é dividi-lo em upstream (exploração, explotação e produção) e downstream (refino, transporte e distribuição).

O termo petróleo refere-se à emulsão de óleo cru, água e gás natural encontrada na natureza. Reservatórios são rochas porosas e permeáveis que contém óleo, gás e água.

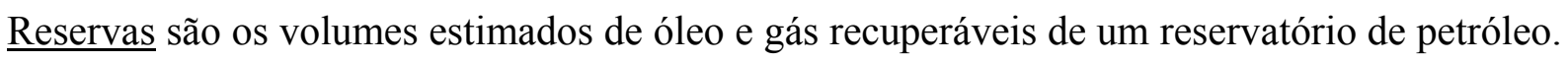
Elas são classificadas em provadas, prováveis e possíveis, de acordo com a probabilidade de os volumes estimados serem economicamente produzidos. Produção é a extração de fluidos dos reservatórios. Esses fluidos são compostos basicamente por hidrocarbonetos e água. Os hidrocarbonetos são compostos por gás natural, condensado e óleo. Condensado é um fluido que se apresenta na forma gasosa nas condições de temperatura e pressão do reservatório e como líquido nas condições padrão de superfície (standard). O líquido do gás natural (LGN) é um líquido extraído do gás natural produzido, através do processamento desse gás em plantas industriais denominadas unidades de processamento de gás natural (UPGN).

A atividade de exploração envolve a descoberta e a delimitação de reservatórios de petróleo através da perfuração de poços exploratórios. A atividade de explotação (também denominada desenvolvimento da produção) envolve a perfuração de poços de desenvolvimento e a instalação de equipamentos para a produção, processamento, injeção, estocagem e transporte de óleo, gás e água. Esses equipamentos são agrupados em estações de 
produção (em terra) ou em plataformas (no mar). A atividade de produção ocupa-se da operação das estações de produção e plataformas.

\section{MODELO DE NEGÓCIOS PARA O SEGMENTO EXPLORAÇÃO E PRODUÇÃO}

Um modelo de negócios é um instrumento para apoio à tomada de decisão. Como todo modelo, é uma simplificação da realidade. Não é necessário, nem viável, detalhar todos os aspectos do sistema em análise. Deve-se, portanto, ter um objetivo claro que permita excluir o que não é relevante. "Sempre modele um problema. Nunca modele um sistema." (STERMAN, 2000, p. 90).

Adota-se um processo de quatro etapas para o desenvolvimento do modelo. A primeira etapa trata do mapeamento da estrutura do sistema. Através de um Diagrama de Subsistemas, identificam-se as principais variáveis envolvidas e definem-se os limites do sistema a ser modelado. Em seguida, classificam-se as variáveis como estoques, fluxos e variáveis auxiliares. Por fim, elabora-se um Mapa de Estoques e Fluxos, identificando as principais relações de causa e efeito entre as variáveis.

A segunda etapa trata do entendimento da dinâmica do sistema. Sobre o Mapa de Estoques e Fluxos, identificam-se os anéis de retroalimentação positiva e negativa mais relevantes.

A terceira etapa trata da identificação das regras de decisão, explícitas ou tácitas, utilizadas para a tomada de decisão. Através de Diagramas de Estrutura das Regras de Decisão, descrevem-se as relações de causa e efeito utilizadas por aqueles que decidem para regular as taxas de fluxo do sistema.

A quarta etapa é a quantificação do modelo. Esta etapa de quantificação não será desenvolvida neste texto.

\subsection{Abordagem ambiente-estratégia-recursos}

O processo decisório de mais alto nível em uma organização refere-se às decisões de caráter estratégico. O modelo hegemônico para a definição de estratégias a partir de 1980 foi a abordagem baseada no mercado. Esta abordagem introduziu no campo da estratégia o paradigma estrutura-conduta-desempenho da Organização Industrial, desenvolvido no campo da economia por Edward S. Mason e Joe Bain. O detalhamento e a divulgação dessa abordagem foram feitos por Michael E. Porter através do livro Competitive Strategy, de 1980. 
A essência da abordagem baseada no mercado é que a estrutura da indústria determina o estado de competição dentro da mesma e define o contexto para a escolha de estratégias pelas empresas, ou seja, sua conduta. A estratégia adotada por cada empresa impacta sua lucratividade, ou seja, seu desempenho.

Por outro lado, ainda na década de 1980, foram desenvolvidos estudos relacionados à abordagem baseada em recursos (resources-based view), tendo como inspiração a obra pioneira de Edith Penrose (1959). Esta abordagem credita a lucratividade das firmas aos baixos custos ou à alta qualidade ou ao desempenho de seus produtos. Ela localiza a vantagem competitiva dentro da firma, em seus recursos "difíceis-de-imitar". Segundo Barney (1996, p. 143-144), esses recursos podem ser classificados em quatro categorias: capital financeiro, capital físico, capital humano e capital organizacional.

Comparando-se a abordagem baseada em recursos com a abordagem baseada no mercado, observa-se uma mudança radical na natureza da competição: ela se desloca dos produtos para os processos. A estratégia, então, passa a ser o controle de recursos escassos.

Embora alguns autores defendam que as duas abordagens são concorrentes, adota-se neste trabalho a premissa de que são complementares, conforme atestam as seguintes declarações:

A visão baseada em recursos é complementar à literatura analítica e empírica baseada na estrutura de Bain-Porter. (MAHONEY e PANDIAN, 1992: 371).

A emergência da visão baseada em recursos da firma ajuda a conciliar esse aparente conflito de abordagens e preencher a promessa da estrutura de Andrews ... reconhece a importância dos recursos e competências específicos da companhia, enquanto eles assim o sejam no contexto do ambiente competitivo. (COLLIS e MONTGOMERY, 1995: 121).

Em coerência com a definição acima, Salaman e Asch (2003, p. 24-27) preconizam que as tentativas de mudar as organizações devem levar em conta as conexões entre estratégia e recursos. $\mathrm{O}$ aperfeiçoamento do desempenho deriva da relação entre três variáveis centrais: ambiente organizacional ou de negócios, estratégia de negócios e recursos organizacionais. $\mathrm{Na}$ essência, qualquer proposta de aperfeiçoar o desempenho de uma organização é uma proposta para aperfeiçoar um ou mais elementos da abordagem ambiente-estratégia-recursos.

\subsection{Diagrama de subsistemas}

O objetivo deste modelo de negócios é fornecer elementos para a tomada de decisão aos responsáveis pelas atividades desenvolvidas no Segmento de Exploração e Produção de uma empresa da indústria do petróleo, seja ela integrada ou restrita a este segmento apenas. A Figura 1 apresenta as variáveis relevantes para a modelagem do sistema e estabelece os 
limites para esse sistema. As variáveis externas a esses limites são denominadas exógenas, as variáveis internas são denominadas endógenas. O critério adotado para a classificação de uma variável como endógena ou exógena é a capacidade de influenciar no seu comportamento: os gestores do segmento de exploração e produção não têm influência relevante sobre as variáveis exógenas.

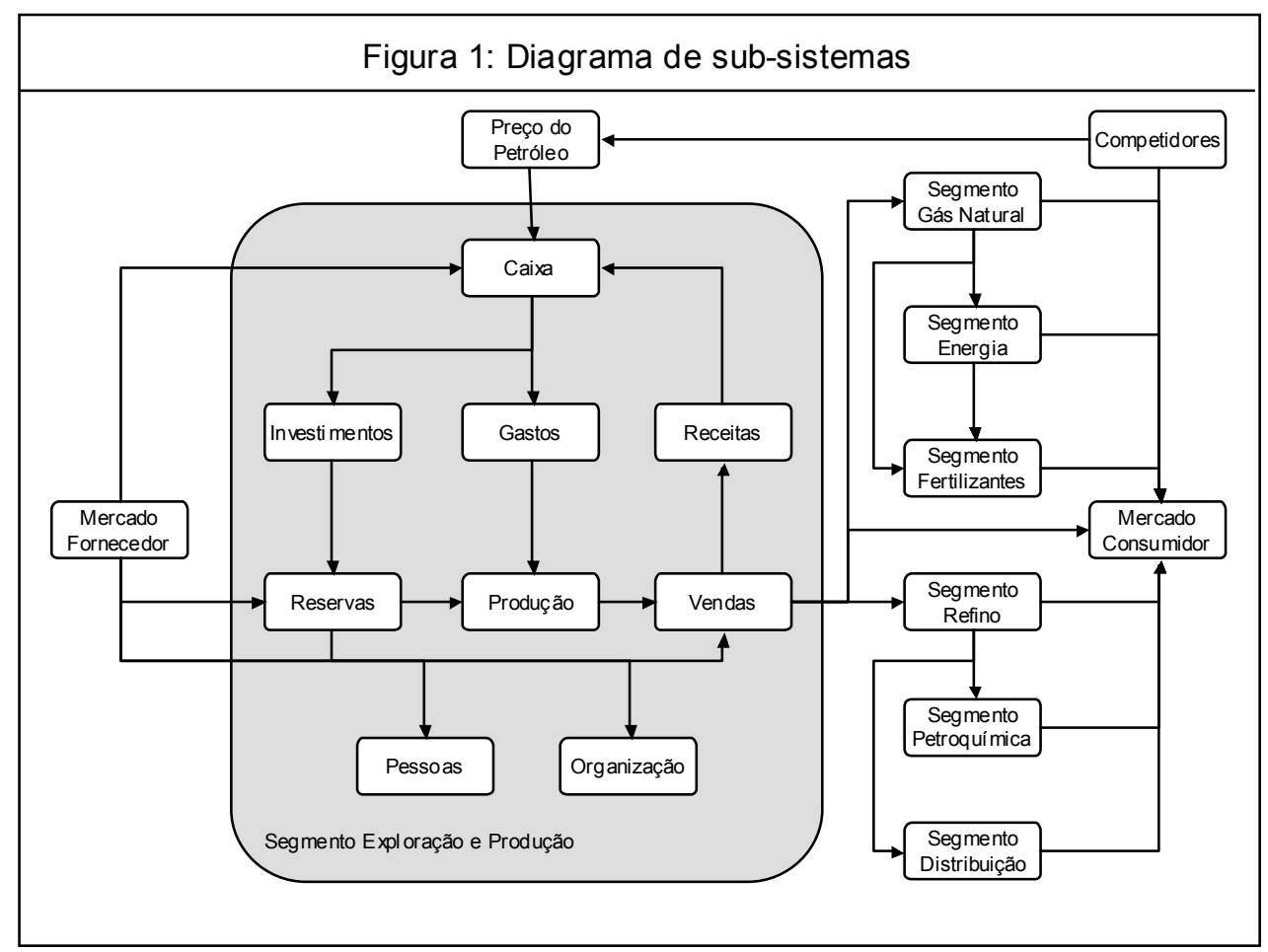

\subsection{Estoques de recursos}

Os recursos tangíveis e intangíveis que uma empresa necessita para desenvolver suas atividades podem ser considerados, à luz da dinâmica de sistemas, como estoques. Algumas das variáveis apresentadas no Diagrama de Subsistemas têm características de estoques. Selecionam-se, a seguir, as mais relevantes para a elaboração do Mapa de Estoques e Fluxos.

O principal recurso físico para o segmento de exploração e produção de petróleo é o volume de reservas sobre o qual a empresa possui direitos de exploração e/ou de produção. $\mathrm{O}$ principal recurso financeiro é o caixa disponível para investimentos em exploração e desenvolvimento da produção, e para cobrir os gastos com custos e despesas das operações de produção. Dentre os recursos de infra-estrutura, o principal é pessoal capacitado para 
desenvolver as atividades técnicas e de negócios dos processos considerados críticos para o segmento.

O volume total de reservas, composto por óleo, gás natural e condensado, é medido em barris de óleo equivalente (boe). Convenciona-se que 6 mil pés cúbicos standard (scf) de gás natural equivalem a um barril de óleo equivalente (boe). O caixa é medido em dólares norte-americanos (US\$). O pessoal capacitado é medido como uma relação percentual (\%) entre o nível de capacitação efetivamente disponível e aquele requerido para os processos críticos. Por nível de capacitação requerido entende-se a quantidade de pessoas certificadas, necessárias para exercer cada uma das atividades técnicas e de negócios dos processos considerados críticos para o segmento.

\subsection{Fluxos de recursos}

Os estoques são regulados por influxo e escoamento. No caso das reservas, o influxo é denominado incorporações e o escoamento é denominado desincorporações, ambos medidos em barris de óleo equivalente por ano (boe/ano). As incorporações de reservas resultam de aquisições, descobertas, desenvolvimento, reavaliações, recuperação secundária e recuperação especial. As desincorporações resultam de vendas, reavaliações e produção.

O influxo para o estoque de caixa é denominado recebimentos e o escoamento é denominado pagamentos, ambos medidos em dólares norte-americanos por ano (US\$/ano). Os recebimentos resultam de vendas de produtos e serviços, aluguéis de instalações e equipamentos, rendimentos de aplicações financeiras, empréstimos contraídos, aportes de capitais recebidos de investidores, dividendos pela participação em ativos, desimobilizações, ganhos cambiais, correção monetária e outros recebimentos eventuais. Os pagamentos resultam da compra de produtos e matérias-primas, salários e encargos pagos a empregados, taxas pagas por serviços prestados, tributos pagos ao governo, aluguéis de instalações e equipamentos, juros, correção e amortizações pagos sobre dívidas, aportes para aquisição de ativos, dividendos pagos a sócios minoritários, investimentos, perdas cambiais, correção monetária e outros pagamentos eventuais.

O influxo para o estoque de pessoal capacitado é denominado capacitação e o escoamento é denominado incapacitação, ambos medidos pela quantidade de pessoas certificadas por ano (certificações/ano). A capacitação resulta da admissão de pessoas certificadas ou da certificação de pessoas que já faziam parte da equipe. A incapacitação resulta da perda de algum colaborador (por transferência, aposentadoria, demissão ou 
falecimento), ou pela mudança no nível de capacitação requerido (exigência de uma nova certificação ou perda da validade de alguma certificação existente).

De forma simplificada, a estrutura do sistema está representada por seu Mapa de Estoques e Fluxos (Figura 2), através das principais relações de causa e efeito entre os três estoques, seus fluxos e demais variáveis auxiliares.

\subsection{Dinâmica do sistema}

Para se entender a dinâmica do sistema, é necessário identificar os anéis de retroalimentação relevantes que atuam neste sistema (Figura 2). $\mathrm{O}$ anel de reforço $\mathbf{R}_{\mathbf{1}}$ indica que, se o volume de reservas aumenta, o volume de vendas de reservas e de produção tende a aumentar. Se o volume de vendas aumenta, os recebimentos tendem a aumentar. Se os recebimentos aumentam, o caixa tende a aumentar. Se o caixa aumenta, o volume de investimentos tende a aumentar. Se o volume de investimentos aumenta, as incorporações tendem a aumentar. Se as incorporações aumentam, o volume de reservas tende a aumentar, gerando um crescimento exponencial no sistema.

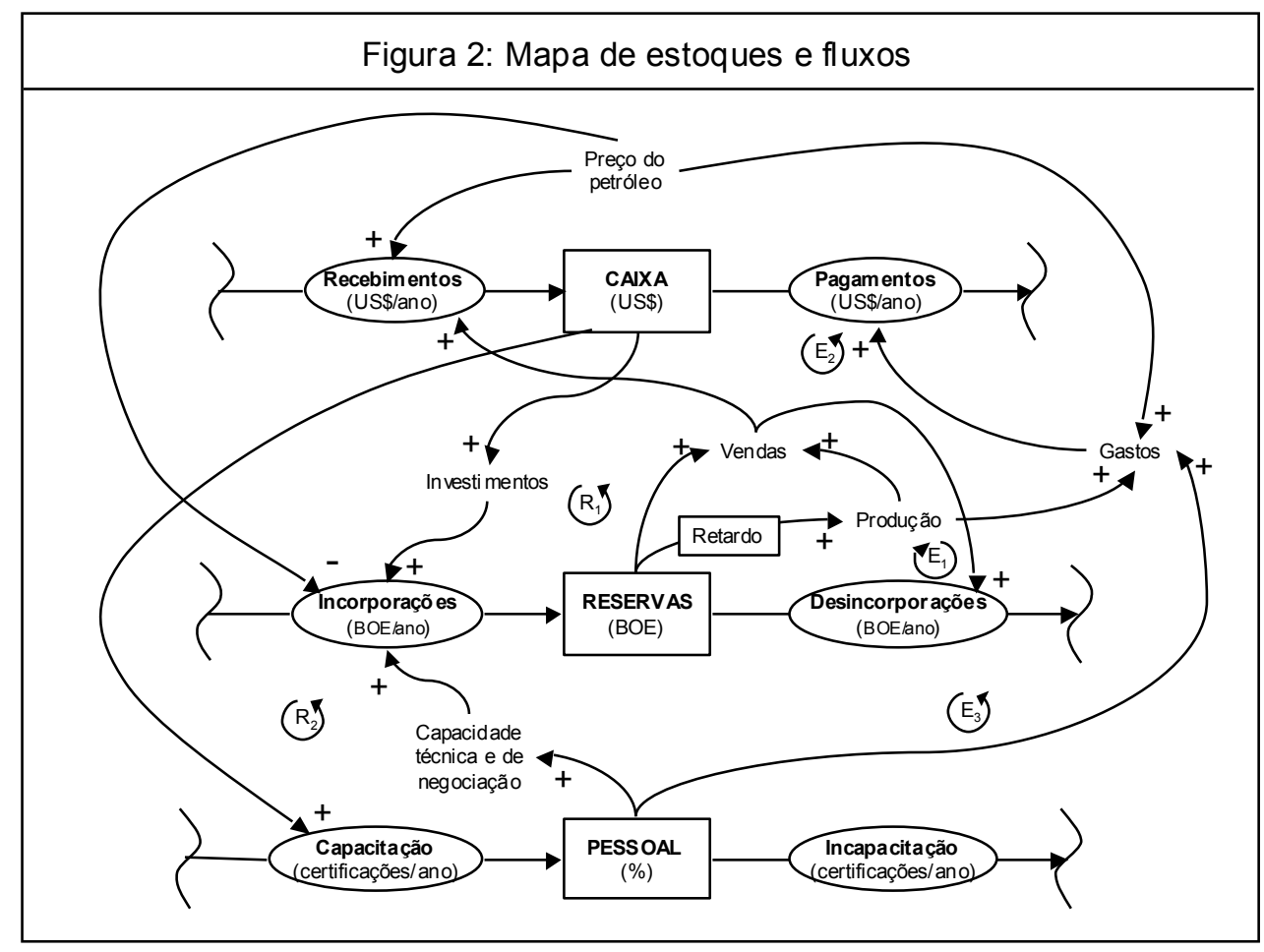

Este ciclo virtuoso, porém, tem limites. $\mathrm{O}$ anel de equilíbrio $\mathbf{E}_{\mathbf{1}}$ indica que, se o volume de vendas aumenta, as desincorporações tendem a aumentar. Se as desincorporações aumentam, o volume de reservas tende a diminuir. Se o volume de reservas diminui, o volume 
de vendas de reservas e de produção tende a diminuir, contrabalançando o crescimento provocado pelo anel de reforço $\mathbf{R}_{\mathbf{1}}$.

Um segundo anel de equilíbrio $\mathbf{E}_{2}$ indica que, se a produção aumenta, os gastos tendem a aumentar. Se os gastos aumentam, os pagamentos tendem a aumentar. Se os pagamentos aumentam, o caixa tende a diminuir. Se o caixa diminui, o volume de investimentos tende a diminuir. Se o volume de investimentos diminui, as incorporações tendem a diminuir. Se as incorporações diminuem, o volume de reservas tende a diminuir. Se as reservas diminuem, a produção tende a diminuir, contrabalançando o crescimento provocado pelo anel de reforço $\mathbf{R}_{\mathbf{1}}$, da mesma forma que o anel de equilíbrio $\mathbf{E}_{\mathbf{1}}$.

$\mathrm{O}$ anel de reforço $\mathbf{R}_{\mathbf{2}}$ indica que, se o caixa aumenta, a capacitação tende a aumentar. Se a capacitação aumenta, o pessoal capacitado tende a aumentar. Se o pessoal capacitado aumenta, a capacidade técnica e de negociação tende a aumentar. Se a capacidade técnica e de negociação aumenta, as incorporações tendem a aumentar. Se as incorporações aumentam, o volume de reservas tende a aumentar. Se o volume de reservas aumenta, o volume de vendas de reservas e de produção tende a aumentar. Se o volume de vendas aumenta, os recebimentos tendem a aumentar. Se os recebimentos aumentam, o caixa tende a aumentar, gerando um crescimento exponencial no sistema.

Neste caso, também, existe um anel de equilíbrio $\left(\mathbf{E}_{\mathbf{3}}\right)$ que contrabalança o crescimento provocado pelo anel de reforço $\left(\mathbf{R}_{2}\right)$. O anel de equilíbrio $\mathbf{E}_{3}$ indica que, se o pessoal capacitado aumenta, os gastos com despesas tendem a aumentar. Se os gastos aumentam, os pagamentos tendem a aumentar. Se os pagamentos aumentam, o caixa tende a diminuir. Se o caixa diminui, a capacitação tende a diminuir. Se a capacitação diminui, o pessoal capacitado tende a diminuir.

\subsection{Regras de decisão}

Os estoques e os fluxos de recursos comportam-se de acordo com critérios tácitos ou explícitos denominados regras de decisão. A tomada de decisão pelos gestores se dá através da intervenção sobre as taxas de fluxo de entrada e saída dos estoques. Observa-se que algumas regras de decisão são quantificáveis e podem ser automatizadas no processo decisório; para a finalidade deste texto convenciona-se chamá-las de diretrizes. Outras regras de decisão são qualitativas e demandam decisão caso a caso; para a finalidade deste texto convenciona-se chamá-las de estratégias. Há, também, variáveis exógenas que interferem nas taxas de fluxo e devem ser levadas em consideração no processo decisório; para a finalidade deste texto convenciona-se chamá-las de condicionantes. 
O Mapa de Estoques e Fluxos utilizado até aqui é muito agregado para viabilizar a identificação de regras de decisão. Utiliza-se, então, Diagramas de Estrutura das Regras de Decisão que são desagregações de partes relevantes do Mapa de Estoques e Fluxos. Nesses diagramas é possível identificar estratégias, diretrizes e condicionantes que atuam sobre as taxas de fluxo do sistema.

Conforme já foi mencionado mais acima, as incorporações de reservas resultam de aquisições, descobertas, desenvolvimento, reavaliações, recuperação secundária e recuperação especial.

A aquisição de reservas é a compra do direito de explorar e/ou desenvolver e/ou produzir óleo e gás natural no mercado secundário de blocos previamente licitados. A Figura

3 apresenta um mapa detalhado dos estoques e fluxos desta atividade. Identificam-se as seguintes estratégias, diretrizes e condicionantes relevantes: (1) Estratégia Exploratória: escolha das regiões de interesse; (2) Diretriz de Investimentos: caixa alocado para investimentos em aquisições; (3) Diretriz de Incorporações: relação reserva-produção (R/P) mínima desejada (piso) e custo de apropriação de reservas (CAR) máximo aceitável (teto); (4) Diretriz de Pessoal: pessoal alocado para selecionar as regiões de interesse e para negociar as aquisições; (5) Condicionante: disponibilidade de reservas nas regiões de interesse.

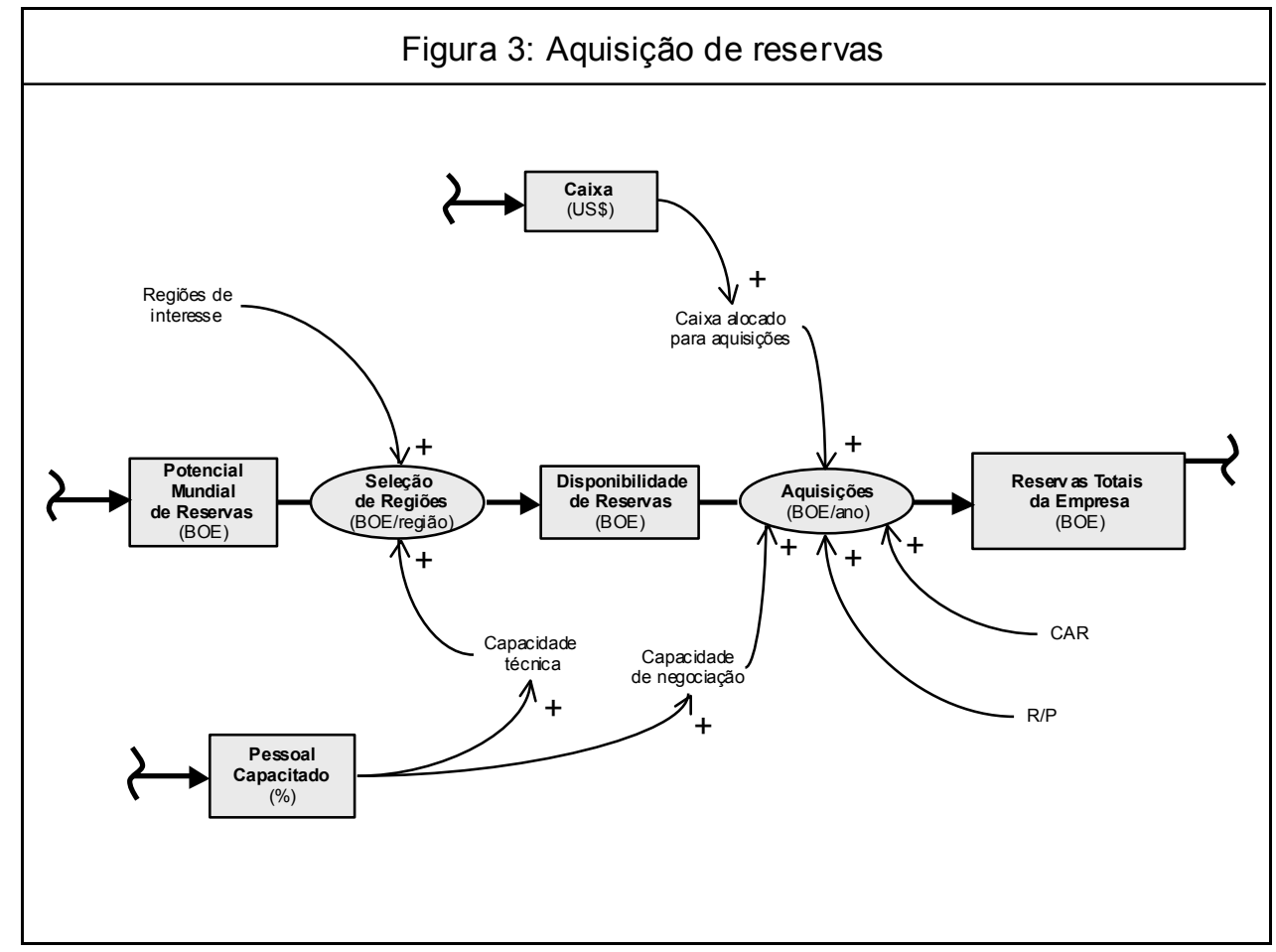

Onde: a relação reserva-produção $(\mathrm{R} / \mathrm{P})$ é o volume de reservas provadas desenvolvidas ao final de um determinado ano, dividido pelo volume produzido durante 
aquele ano. Fornece uma estimativa do número de anos que restam de produção; o custo de apropriação de reservas (CAR) é o investimento associado à aquisição de novas reservas, exploração e desenvolvimento incorrido num período de 5 anos, dividido pelo volume de óleo equivalente apropriado como reservas provadas desenvolvidas no mesmo período. Adota-se um período de 5 anos com base no tempo médio das fases exploratórias dos contratos ( 3 anos) adicionado ao tempo médio das fases de avaliação (appraisal) e dos programas de desenvolvimento necessários para provar as reservas ( 2 anos); o potencial mundial de reservas é a variável exógena que representa o volume de reservas potencialmente disponível no mundo; a disponibilidade de reservas é a variável exógena que representa o volume de reservas disponível no mercado das regiões de interesse; e as reservas totais da empresa são as reservas provadas desenvolvidas e não desenvolvidas (P1), mais as reservas prováveis (P2), mais as reservas possíveis $(\mathrm{P} 3)$.

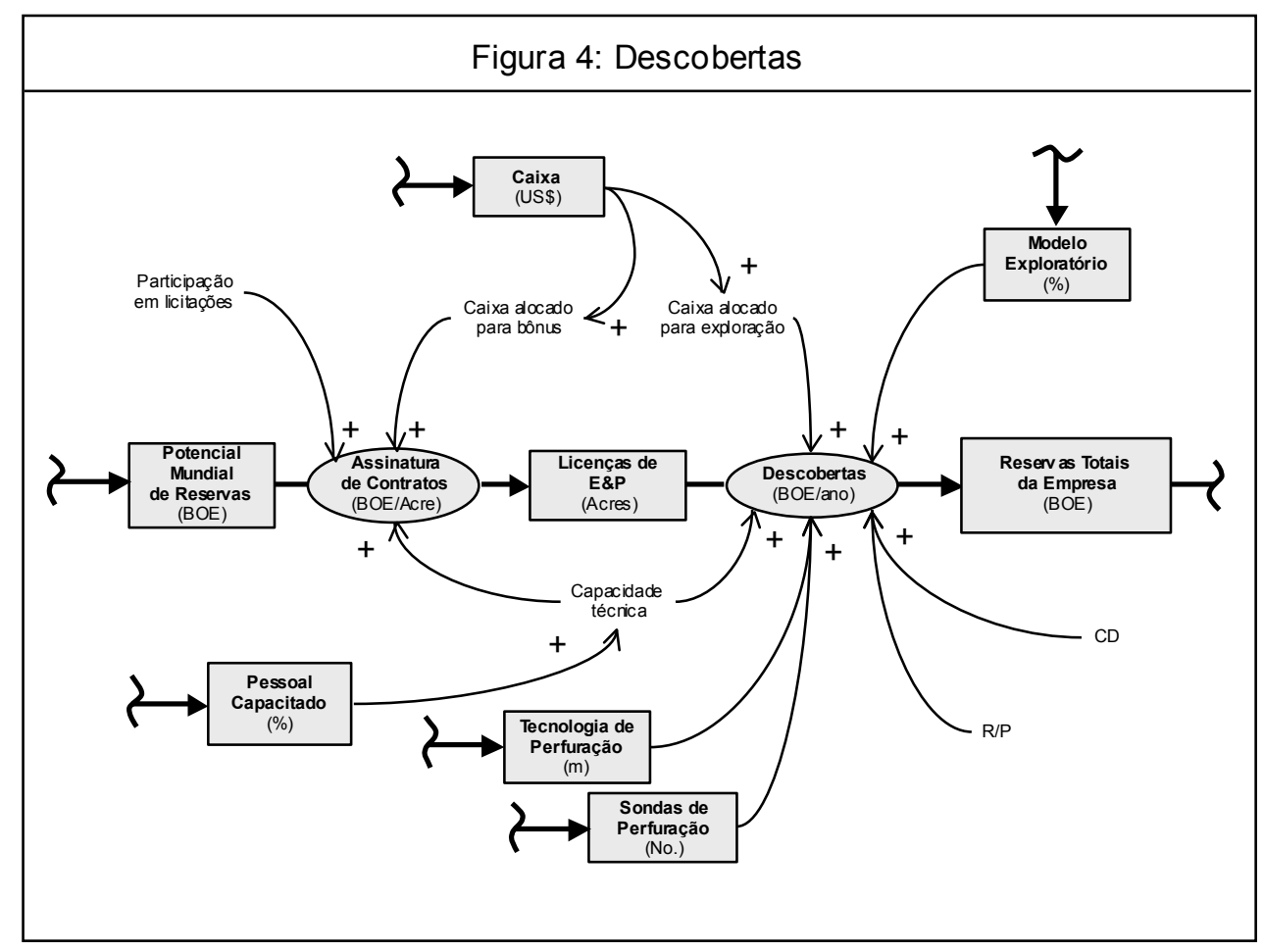

As descobertas comerciais são o resultado da perfuração de poços exploratórios que encontraram petróleo em condições comerciais de produzir. Dependem da participação em licitações de blocos, de forma a obter licenças para exploração e/ou desenvolvimento e/ou produção de óleo e gás natural. A Figura 4 apresenta um mapa detalhado dos estoques e fluxos desta atividade. Identificam-se as seguintes estratégias, diretrizes e condicionantes relevantes: (1) Estratégia Exploratória: intensidade e tipo de participação em licitações; (2) 
Diretriz de Investimentos: caixa alocado para investimentos em bônus e em exploração; (3) Diretriz de Exploração: relação reserva-produção (R/P) mínima desejada (piso) e custo de descoberta (CD) máximo aceitável (teto); (4) Diretriz de Pesquisa e Desenvolvimento: novas tecnologias de perfuração dominadas; (5) Diretriz de Pessoal: pessoal alocado para a seleção de licitações, para a modelagem das áreas licitadas e para as demais atividades de exploração; (6) Condicionante: quantidade de sondas de perfuração disponíveis. Onde: as licenças de E\&P são as áreas licenciadas para exploração e produção; o custo de descoberta (CD) é o investimento em exploração incorrido num período de 3 anos, dividido pelo volume de óleo equivalente economicamente recuperável descoberto no mesmo período. Adota-se um período de 3 anos com base no tempo médio das fases exploratórias dos contratos.

A atividade de desenvolvimento consiste em provar volumes prováveis e possíveis, e transformar as reservas provadas não desenvolvidas em desenvolvidas. A Figura 5 apresenta um mapa detalhado dos estoques e fluxos desta atividade. Identificam-se as seguintes diretrizes e condicionantes relevantes:

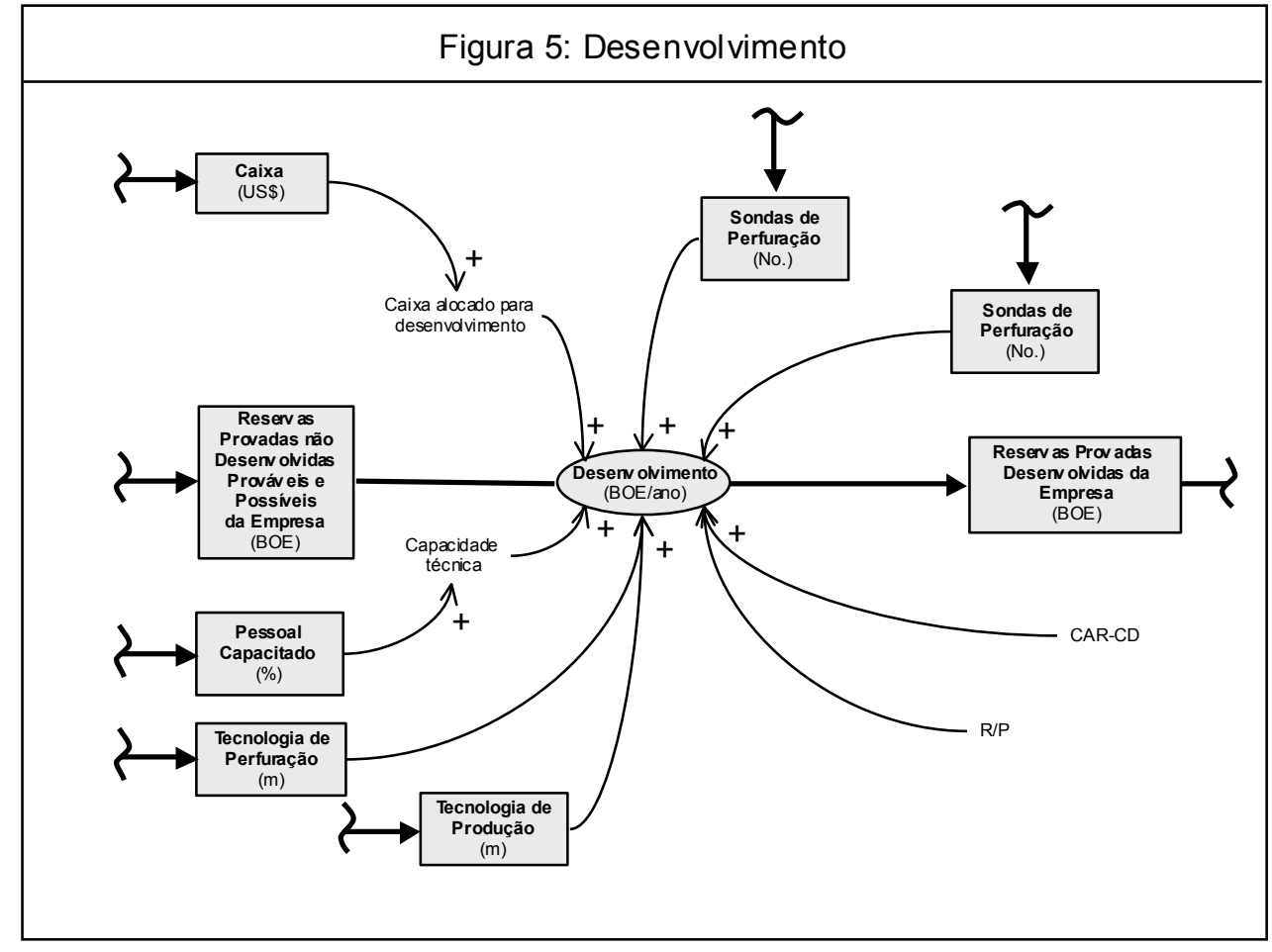

(1) Diretriz de Investimentos: caixa alocado para desenvolvimento; (2) Diretriz de Desenvolvimento: relação reserva-produção (R/P) mínima desejada (piso) e custo de desenvolvimento (CAR-CD) máximo aceitável (teto); (3) Diretriz de Pesquisa e Desenvolvimento: novas tecnologias de perfuração e de produção dominadas; (4) Diretriz de Pessoal: pessoal alocado para as atividades de desenvolvimento; (5) Condicionantes: 
quantidade de sondas de perfuração e de produção disponíveis. Onde: as reservas provadas desenvolvidas da empresa são as reservas que dispõem de toda a infra-estrutura necessária para produção em condições comerciais.

As reavaliações são aumentos ou reduções nos volumes de reservas em função de dados técnicos sobre o comportamento dos reservatórios, em função dos preços do óleo e do gás natural e em função de novas tecnologias que tornam essas reservas comercias ou subcomerciais. A Figura 6 apresenta um mapa detalhado dos estoques e fluxos desta atividade. Identificam-se as seguintes diretrizes e condicionantes relevantes: (1) Diretriz de Pesquisa e Desenvolvimento: novas tecnologias de produção dominadas; (2) Diretriz de Pessoal: pessoal alocado para as atividades de reavaliação; (3) Condicionantes: preços do óleo e do gás natural.

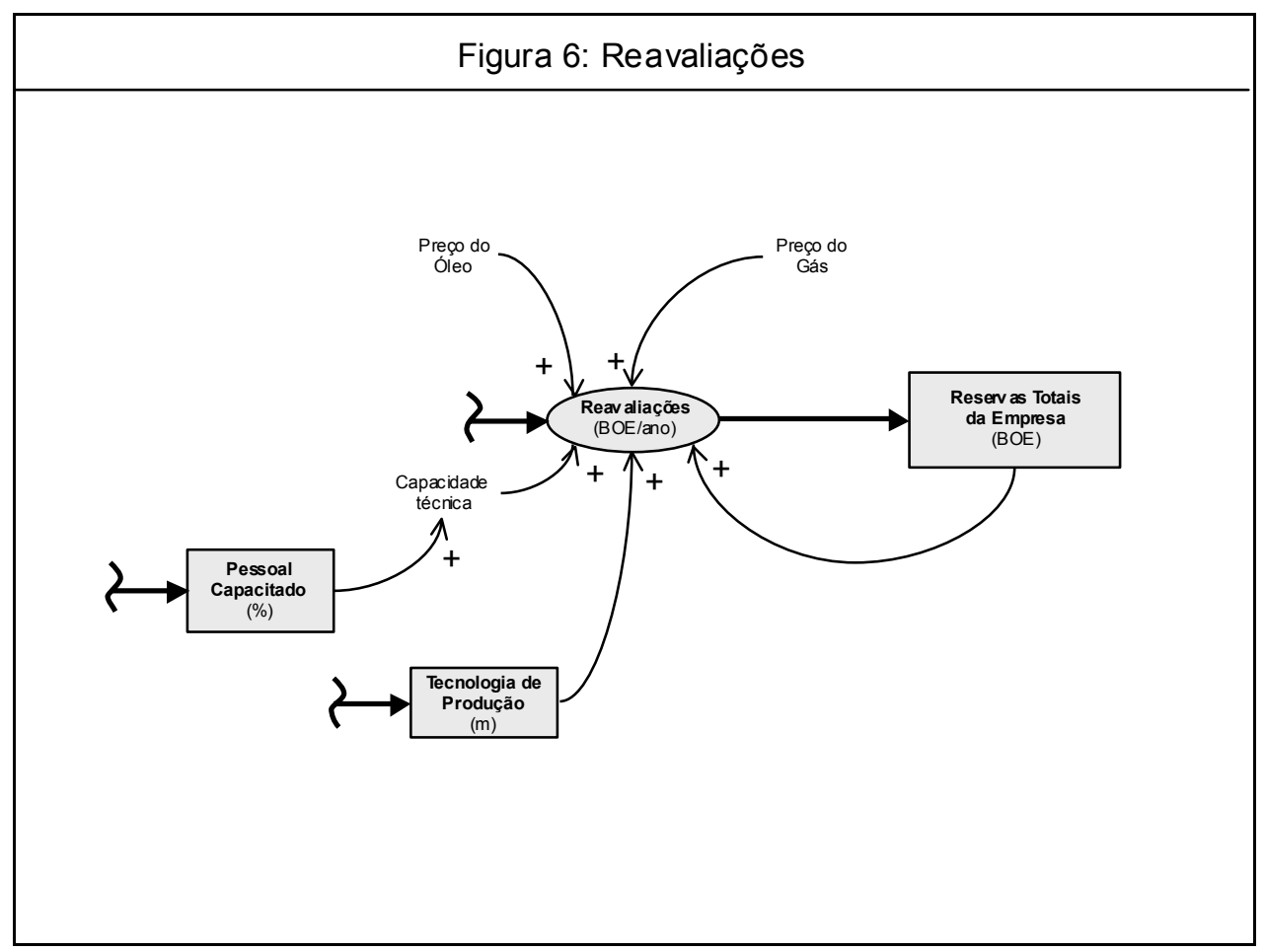




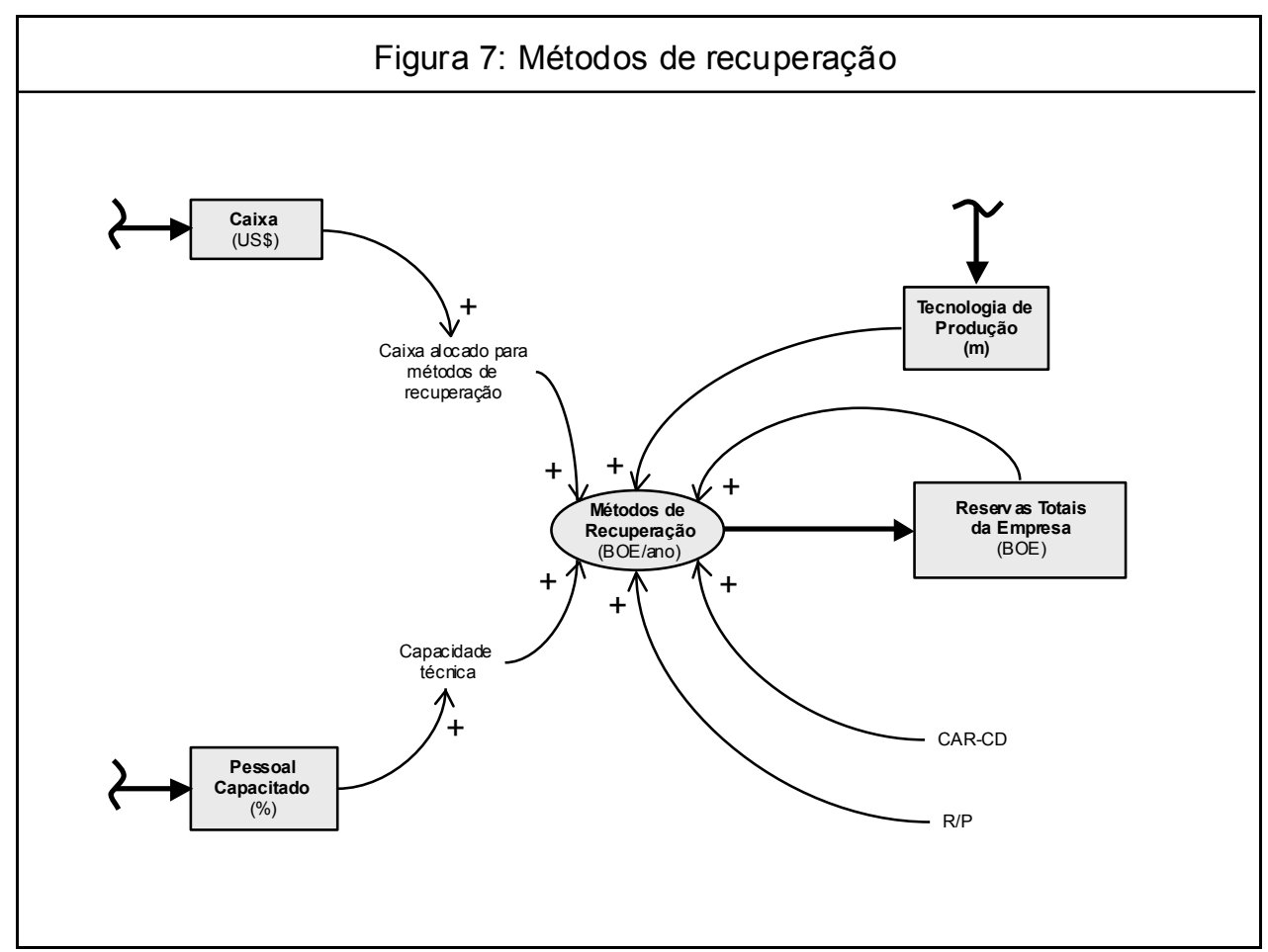

Os métodos de recuperação secundária e melhorada (enhanced) são tecnologias aplicadas aos reservatórios de petróleo que aumentam o fator de recuperação. Fator de recuperação é o volume de óleo que poderá ser extraído dos reservatórios, dividido pelo volume total de óleo existente nos reservatórios (oil in place). A Figura 7 apresenta um mapa detalhado dos estoques e fluxos desta atividade. Identificam-se as seguintes diretrizes relevantes: (1) Diretriz de Investimentos: caixa alocado para métodos de recuperação; (2) Diretriz de Desenvolvimento: relação reserva-produção $(\mathrm{R} / \mathrm{P})$ mínima desejada (piso) e custo de desenvolvimento (CAR-CD) máximo aceitável (teto); (3) Diretriz de Pesquisa e Desenvolvimento: novas tecnologias de métodos de recuperação dominadas; (4) Diretriz de Pessoal: pessoal alocado para as atividades de métodos de recuperação. As desincorporações resultam de vendas, reavaliações e produção. 


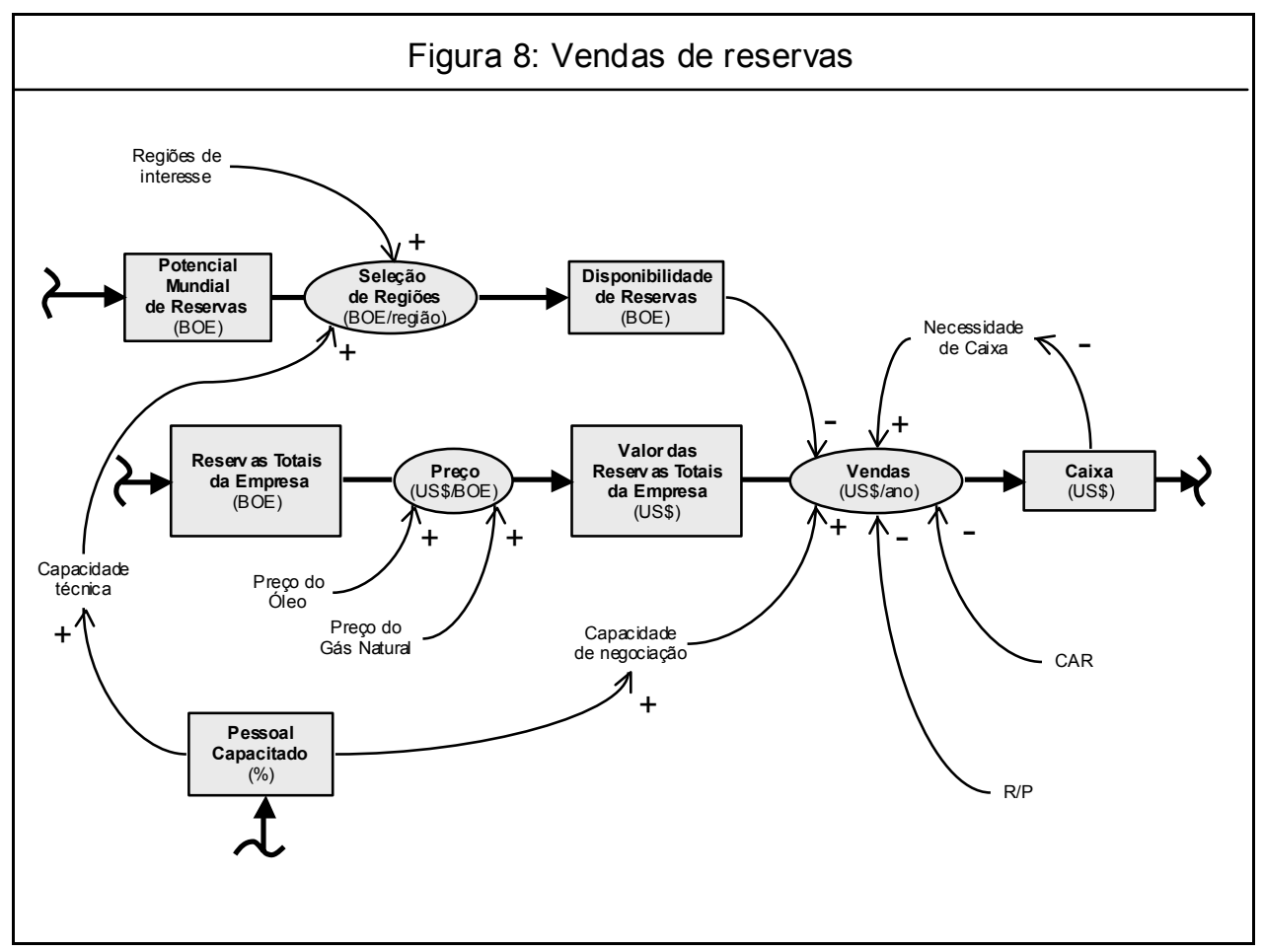

A venda de reservas é a venda do direito de explorar e/ou desenvolver e/ou produzir óleo e gás natural, no mercado secundário de blocos já licitados. A Figura 8 apresenta um mapa detalhado dos estoques e fluxos desta atividade. Identificam-se as seguintes estratégias, diretrizes e condicionantes relevantes: (1) Estratégia Exploratória: escolha das regiões de interesse; (2) Diretriz de Investimentos: necessidade de caixa; (3) Diretriz de Desincorporações: relação reserva-produção (R/P) mínima desejada (piso) e custo de apropriação de reservas (CAR) máximo aceitável (teto); (4) Diretriz de Pessoal: pessoal alocado para selecionar as regiões de interesse e para negociar as vendas; (5) Condicionantes: disponibilidade de reservas nas regiões de interesse, preços do óleo e do gás natural.

As reavaliações já foram analisadas mais acima.

A produção de óleo e condensado é a extração de hidrocarbonetos líquidos dos reservatórios. A produção de gás natural é a extração de hidrocarbonetos gasosos dos reservatórios. A produção de líquido de gás natural (LGN) é a extração de hidrocarbonetos líquidos do gás natural produzido, através do processamento desse gás em plantas industriais denominadas unidades de processamento de gás natural (UPGN). 


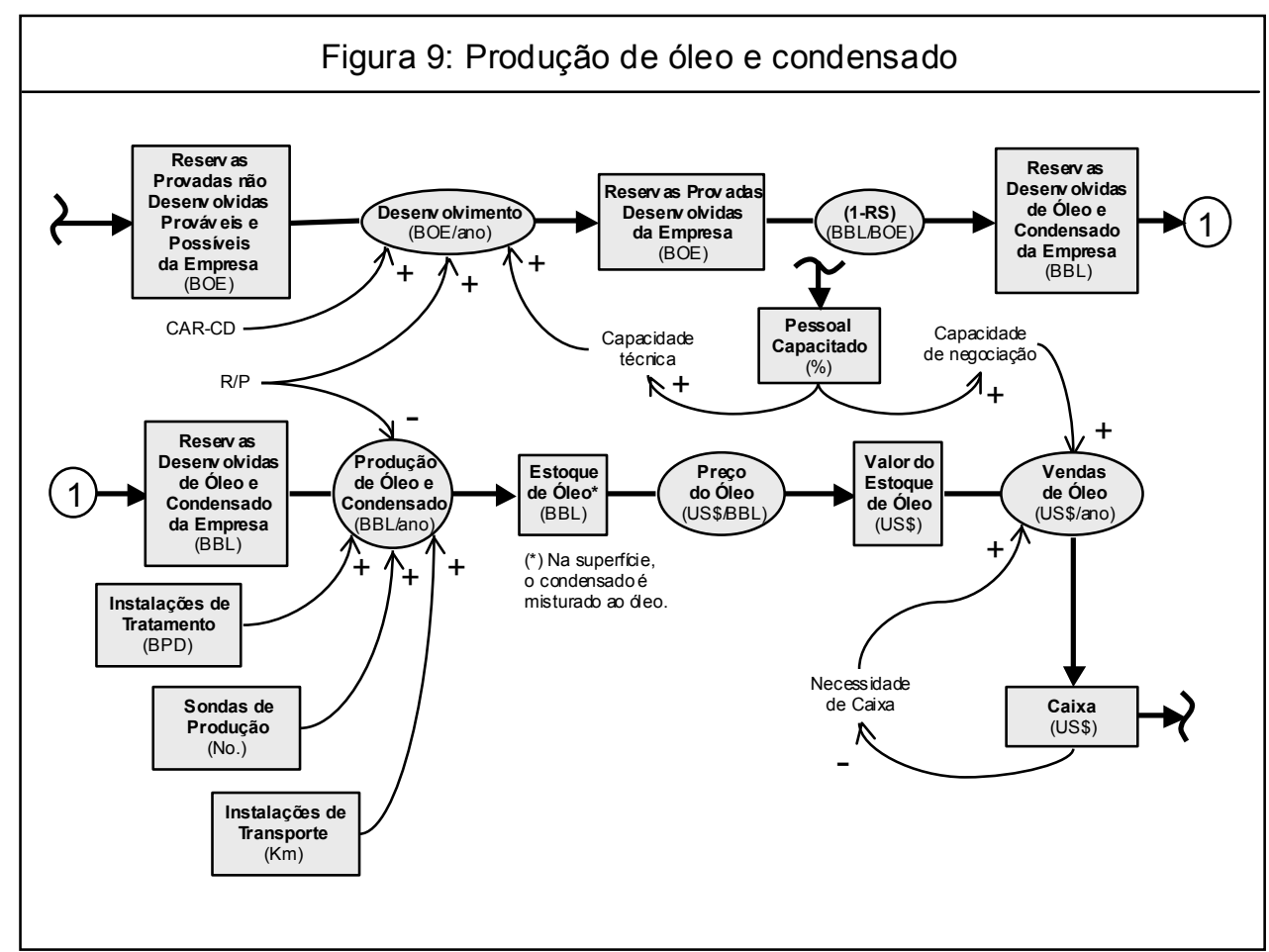

A Figura 9 apresenta um mapa detalhado dos estoques e fluxos da atividade de produção de óleo e condensado. Identificam-se as seguintes diretrizes e condicionantes relevantes: (1) Diretriz de Investimentos: capacidade instalada para tratamento e transporte de óleo; (2) Diretriz de Produção: relação reserva-produção (R/P) mínima desejada (piso); (3) Diretriz de Pessoal: pessoal alocado para negociar as vendas; (4) Condicionantes: quantidade de sondas de produção disponíveis e preço do óleo.

A Figura 10 apresenta um mapa detalhado dos estoques e fluxos da atividade de produção de gás natural. Identificam-se as seguintes diretrizes e condicionantes relevantes: (1) Diretriz de Investimentos: capacidade instalada para tratamento e transporte de gás natural; (2) Diretriz de Produção: relação reserva-produção (R/P) mínima desejada (piso); (3) Diretriz de Pessoal: pessoal alocado para negociar as vendas; (4) Condicionantes: quantidade de sondas de produção disponíveis e preço do gás natural.

A Figura 11 apresenta um mapa detalhado dos estoques e fluxos da atividade de produção de líquido de gás natural (LGN). Identificam-se as seguintes diretrizes e condicionantes relevantes: (1) Diretriz de Investimentos: capacidade instalada para processamento de gás natural e transporte do LGN; (2) Diretriz de Pessoal: pessoal alocado para operar as UPGN e para negociar as vendas; (3) Condicionante: preço do LGN. 

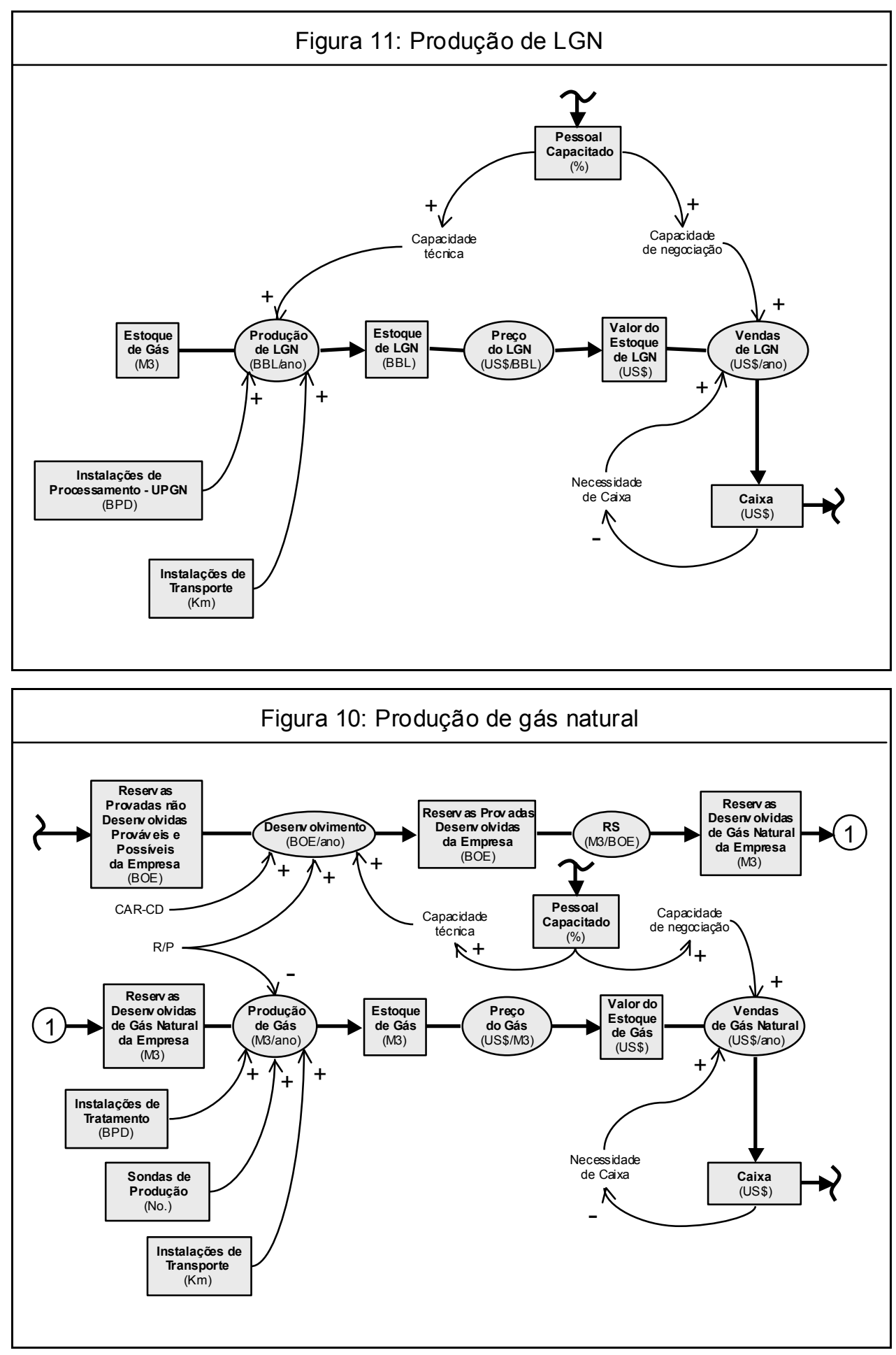

\subsection{Análise do modelo}

A aplicação dos conceitos de racionalidade limitada, modelos mentais, dinâmica de sistemas e abordagem ambiente-estratégia-recursos no desenvolvimento de um modelo de negócios para o segmento exploração e produção de petróleo resultou em constatações e conclusões importantes sobre o processo decisório de nível estratégico: 
- Ao estruturar-se o modelo de acordo com a analogia de estoques e fluxos da dinâmica de sistemas, os recursos foram considerados como estoques. Esta é uma consideração importante, pois é sobre os recursos (e não sobre o mercado) que a organização detém poder de decisão, e são os estoques que definem o estado do sistema e fornecem as informações necessárias para a tomada de decisão.

- A abordagem de recursos os agrupa em quatro categorias: capital financeiro, capital físico, capital humano e capital organizacional. No caso do segmento E\&P identificaram-se três recursos relevantes: caixa (capital financeiro), reservas (capital físico) e pessoal capacitado (capital humano). Com relação ao capital organizacional, não se identificou nenhum recurso específico relevante. Pode-se afirmar que o capital organizacional resulta da interação dos estoques (recursos) e seus fluxos.

- A análise detalhada das regras de decisão indicou que elas têm características diferentes e podem ser agrupadas em três categorias: diretrizes, estratégias e condicionantes. As diretrizes são quantificáveis e podem ser automatizadas no processo decisório, as estratégias são qualitativas e demandam decisão caso a caso e os condicionantes são variáveis exógenas que interferem nas taxas de fluxo e devem ser levadas em consideração no processo decisório.

- Identificaram-se diretrizes relativas a investimentos, incorporações, exploração, pesquisa e desenvolvimento, desincorporações, produção e pessoal. A sua explicitação permite aos executivos de nível estratégico manterem o foco de suas decisões na estratégia, favorece a delegação para os níveis tático e operacional da organização e sua utilização torna mais sólido e ágil o processo decisório.

- Identificaram-se estratégias relativas à escolha das regiões de interesse, à intensidade e ao tipo de participação em licitações. A percepção de sua importância pelos formuladores da estratégia da organização é fundamental. Tratam-se de decisões que não podem ser delegadas e que geram vantagens relevantes em relação aos competidores.

- Identificaram-se condicionantes relativos à disponibilidade de reservas nas regiões de interesse, à quantidade de sondas de perfuração e produção disponíveis no mercado, aos preços do óleo, do gás natural e do LGN. Tratam-se de variáveis que causam grande impacto no desempenho e estão fora do controle da organização. Devem, portanto, ser objeto de acompanhamento sistemático, de análise de indicadores de tendência, de geração de projeções e de esquemas de reação rápida para amenizar impactos danosos. 


\section{CONCLUSÕES}

Este trabalho desenvolveu um modelo de negócios para organizações complexas que foi aplicado às atividades do segmento exploração e produção de petróleo, empregando conceitos de racionalidade limitada, modelos mentais, dinâmica de sistemas e abordagem ambiente-estratégia-recursos no processo decisório.

O desenvolvimento e a posterior análise do modelo revelaram aspectos relevantes para os gerentes responsáveis pela atividade de análise estratégica e para os executivos responsáveis pelas decisões, ao explicitar e hierarquizar as regras de decisão. Sabe-se, agora, que há regras que são quantificáveis e podem ser automatizadas no processo decisório (diretrizes), outras que são qualitativas e demandam decisão caso a caso (estratégias) e um terceiro grupo de regras que interferem no processo, mas são exógenas, ou seja, sobre as quais não é possível ação direta (condicionantes).

As diretrizes podem ser delegadas, permitindo aos executivos e gerentes concentrar seus esforços nas estratégias. Os condicionantes devem ser levados em consideração no processo decisório através de um monitoramento ambiental constante. A incorporação desses novos conhecimentos ao processo decisório o torna mais sólido e ágil, além de facilitar a delegação para os níveis tático e operacional da organização.

A quantificação do modelo conceitual, próxima etapa desta pesquisa, vai utilizar programas disponíveis no mercado que permitem a programação de modelos de estoques e fluxos, gerando "simuladores de vôo". Simuladores de vôo são programas aplicativos que disponibilizam modelos complexos através de interfaces amigáveis. Esses simuladores serão fundamentais na operacionalização do modelo, pois facilitarão a sua utilização por analistas e executivos nas decisões do dia-a-dia.

A extensão do modelo conceitual para outros segmentos da indústria do petróleo e a correspondente construção de simuladores seria desejável, considerando os ganhos devidos às sinergias. O desenvolvimento de modelos de negócios semelhantes para outras organizações complexas requer apenas algumas adaptações, visto que os conceitos fundamentais utilizados são robustos.

Uma possível limitação do modelo, que será testada quando da sua quantificação, é o fato de o capital organizacional não estar explicitamente representado no modelo.

\section{REFERÊNCIAS}

ACKOFF, R. L. Redesigning the future: a systems approach to societal planning. New York: John Wiley, 1974. 
ACKOFF, R. L. The future of operational research is past. Journal of the operational research society. p. 93-104. 1979.

BARNEY, Jay B. Gaining and sustaining competitive advantage. Reading: AddisonWesley, 1996.

COLLIS, David J.; MONTGOMERY, Cynthia A. Competing on resources strategy in the 1990s. Harvard business review, july/aug. 1995.

CORBEN, D.; STEVENSON, R.; WOLSTENHOLME, E. F. Holistic oilfield value management. Jornal of the Operacional Research Society, v.50, n.4, p.383-391, 1999.

DOYLE, J.; FORD, D. Mental models concepts for system dynamics research. System dynamics review, v.14, n.1, p. 3-29, 1998.

DYNER, I.; FRANCO, C. J. Consumers' bounded rationality: the case of competitive energy markets. Systems Research and Behavioral Science, v.21, n.4, p.373-389, jul./ago. 2004.

FORRESTER, Jay W. Industrial dynamics. Cambridge: MIT Press, 1961.

FORRESTER, Jay W. Policies, decisions, and information sources for modeling. In: MORECROFT, John D. W.; STERMAN, John D. (ed.). Modeling for learning organizations. Portland: Productivity Press, 1994. Part I, chap. 3, p. 51-84.

GOFFMAN, E. Frame analysis. Harmondsworth: Penguin Books, 1974.

HAFEEZ, K.; ABDELMEGUID, H. Dynamics of human resource and knowledge management. Jornal of the Operacional Research Society, v.54, n.2, p.153-164, 2003.

MAHONEY, Joseph T.; PANDIAN, J. Rajendran. The resource-based view within the conversation of strategic management. Strategic management journal. [s.1.], v. 13, p. 363$380,1992$.

MEADOWS, D. H. Whole earth models and systems. Coevolution quarterly. Summer, 98108. 1982.

PAPERT, S. Mindstorms. New York: Basic Books, 1980.

PENROSE, E. T. The theory of the growth of the firm. Nova York: Wiley, 1959.

PIDD, Michael. Modelagem empresarial: ferramentas para tomada de decisão. Tradução de Gustavo Severo de Borba. Porto Alegre: Artes Médicas, 1998.

PORTER, Michael E. Competitive strategy: techniques for analyzing industries and competitors. New York: Free Press, 1980.

SALAMAN, Graeme; ASCH, David. Strategy and capability: sustaining organizational change. Oxford: Blackwell, 2003. 
SCHÖN, D. A. The reflective practitioner: how professionals think in action. New York: Basic Books, 1982.

SIMON, H. A. Administrative behavior: a study of decision-making processes in administrative organizations. 2. ed. New York: Macmillan, 1957.

STERMAN, John D. Business dynamics: systems thinking and modeling for a complex world. Boston: McGraw-Hill, 2000.

TUSTIN, A. The mechanism of economic systems. Cambridge: Harvard University Press, 1953.

VENNIX, J. Mental models and computer models. 1990. PhD Thesis - Nijmegen Institute of Cognition Reserch and Information Technology, Nijmegen, The Netherlands.

Artigo Recebido em 09/09/2005 e aceito para publicação em 20/09/2005. 